\title{
SIMPLIFIED \\ LIQUID-LIQUID EXTRACTION METHOD COUPLED WITH LC/DAD BY QUANTITATIVE DETERMINATION OF RISPERIDONE IN HUMAN SERUM
}

\author{
SIGRID MENNICKENT $I^{*}$; MARTA DE DIEGO ${ }^{\prime}$;BERND LISER ${ }^{l}$; LINA TRUJILLO ${ }^{l}$ \\ ${ }^{1}$ Department of Pharmacy, Faculty of Pharmacy, University of Concepción, P.O. Box 237, Concepción, Chile.
}

\begin{abstract}
Risperidone, an antipsychotic drug, was determined in human serum, using an optimized liquid-liquid extraction for isolation from biological fluid, with ethyl acetate as extraction solvent. This sample extraction method was chosen to increase extraction efficiency and reduce matrix interferences. Quantitation was achieved by LC/DAD at $294 \mathrm{~nm}$ over the concentration range of $1 \mathrm{ng} / \mathrm{mL}$ to $60 \mathrm{ng} / \mathrm{mL}$ ( $\mathrm{r}=0.999)$. Desipramine was used as internal standard (tR for Risperidone: 4.23; tR Desipramine: 7.31). Mobile phase was water: acetonitrile: triethilamine: glacial acetic acid (70:29.16:0.52: 0.33 v/v), using a Purosphere STAR RP-18e $250 \times 4.5 \mathrm{~mm}(5 \mu)$ column. RSD, for the intra-assay study, was between $0.52 \%-2.09 \%(\mathrm{n}=3)$, and between $0.79 \%-3.25 \%$ ( $=9)$ for the inter-assay. LOD was $0.40 \mathrm{ng} / \mathrm{mL}$ and LOQ was $0.87 \mathrm{ng} / \mathrm{mL}$. Recovery percentage for the accuracy study was between $90.82 \%$ and $98.56 \%((\mathrm{RSD} \leq 3.93)$.

The method is simple, fast, precise, accurate, sensible and selective. This method was successfully applied to quantify risperidone in patient serum samples. In conclusion, the method is useful for quantitative determination of risperidone in human serum.
\end{abstract}

Key words: Risperidone, human serum, liquid chromatography, quantitative determination.

\section{INTRODUCTION}

Risperidone (Fig. 1) is an antipsychotic drug used for the symptomatic management of psychotic disorders, especially in patients with schizophrenia, and, generally, is required for long-term stabilization to sustain symptom remission or control and to minimize the risk of relapse ${ }^{1-2}$.

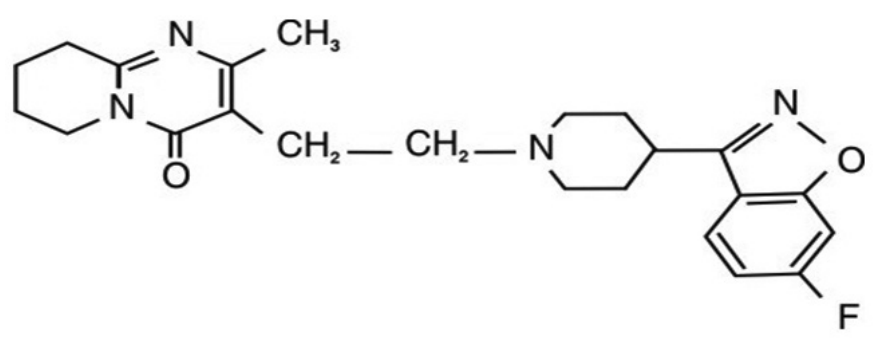

Figure 1: Chemical structure of risperidone.

Risperidone is administered orally or by intramuscular injection. About $90 \%$ of patients receive the drug orally. Oral administration can be in a oncedaily dose or in two equally divided doses daily, with a target dosage of $4 \mathrm{mg}$ daily in most of patients. After normalization to a dose of $4 \mathrm{mg} /$ day, median concentrations had been of $9 \mathrm{ng} / \mathrm{mL}(80 \%$ range, $0.9-27.9 \mathrm{ng} / \mathrm{mL})$ for the parent compound and $24.1 \mathrm{ng} / \mathrm{mL}$ ( $80 \%$ range, $12.0-57.6 \mathrm{ng} / \mathrm{mL}$ ) for the metabolite, 9-hydroxy-risperidone ${ }^{3-4}$

Although antipsychotic drugs have been effective in reducing symptoms of schizophrenia, issues with adherence to these agents continue to be a barrier to the implementation and delivery of a successful treatment plan. Non-adherence lies on a spectrum, is often covert, and is underestimated by clinicians, but affects between $50 \%-60 \%$ of patients with schizophrenia. It increases the risk of relapse, re-hospitalization, self-harm and inpatient costs, leads to lowers quality of life, greater use of emergency psychiatric services, functional decline, and increased risk of death. Recognizing that all patients with schizophrenia are at risk for medication non-adherence is important. No one technique has been shown to be most effective; therefore, the risk for nonadherence should continually be assessed ${ }^{5-9}$.

There are some indirect ways to evaluate the pharmacotherapy adherence of the patients, but these are subjective, depending on confident of patient to response with trustiness ${ }^{10}$.

The determination of drug levels in biological fluids provides objective information. Therefore, drug monitoring of patients biological fluids can be a useful tool to evaluate adherence by relating the serum or plasma levels of drugs with pharmacotherapy compliance ${ }^{10-11}$.

For determination of risperidone in blood, some HPLC 12-16 and spectrophotometric ${ }^{17}$ methods have been reported. All of these methods used human plasma.

In view of the clinical and analytical challenger, the present study describes the development of environment friendly, simple, rapid, sensitive, accurate and precise LC/DAD method. Among all different detectors used to analyze risperidone (evaporative light scattering detector: ELSD, refractive index detector: RID, UV, MS), UV-DAD is simplest and suitable for the purpose of this work. Moreover, serum instead plasma as blood sample allows a simple extraction of analyte from matrix.

Therefore, the aim of this study was to develop and validate a simple, rapid sensitive, accurate and precise LC/DAD method for quantification of risperidone in human serum, suitable for pharmacotherapy adherence studies.

\section{EXPERIMENTAL}

2.1. Chemicals and reagents

USP standards of risperidone and desipramine were purchased from Sigma- Aldrich, St. Louis, MO. Methanol, acetonitrile, triethilamine, glacial acetic acid and ethyl acetate, were obtained from Merck, Darmstadt, Germany. All of the reagents were pro-analysis quality.

\subsection{Preparation of standard solutions}

Stock solutions of $1 \mathrm{mg} / \mathrm{mL}$ of risperidone were prepared by dissolving in methanol. Different concentrations required for preparation of spiking serum calibration and quality control samples were subsequently prepared, to obtain working solutions of 5,30 and $60 \mathrm{ng} / \mathrm{mL}$. All of solutions were stored at 2-8 ${ }^{\circ} \mathrm{C}$ for about two days.

\subsection{Spiking procedure for calibration and quality control (QC)} samples

Calibrator samples were prepared just prior to extraction by spiking $2 \mathrm{~mL}$ of pooled human blank serum with. $1 \mathrm{~mL}$ of a convenient working solution of fluoxetine in methanol, to give concentrations of 1, 5, 20, 30, 45 and $60 \mathrm{ng} / \mathrm{mL}$.

Quality control samples were prepared at concentrations of 5, 30 and 60 $\mathrm{ng} / \mathrm{mL}$, and used to determine the intra and inter-assay precision and accuracy of the method.

Drug-free serum used for the validation of the method was obtained from healthy volunteers, with informed consent. 


\subsection{Sample preparation}

Human blank serum and human serum samples were taken out from deep freezer maintained at $-20{ }^{\circ} \mathrm{C}$, and kept at room temperature for 45 minutes for thawing. Then, $2 \mathrm{~mL}$ of sample was processed by adding initially $25 \mu \mathrm{L}$ of desipramine (internal standard) $(0.5 \mathrm{ng} / \mathrm{mL})$ and $3 \mathrm{~mL}$ of ethyl acetate to the solution, which was subsequently vortex for $5 \mathrm{~min}$ and then centrifuged at $13200 \mathrm{rpm}$ for $5 \mathrm{~min}$. The supernatant was transferred to an Eppendorf tube and evaporated to dryness for $80 \mathrm{~min}$ at $45^{\circ} \mathrm{C}$. The dry residue was reconstituted in $200 \mu \mathrm{L}$ of mobile phase, and a $20 \mu \mathrm{L} \mathrm{mL}$ aliquot of this solution injected for analysis.

\subsection{Instrumentation and chromatographic conditions}

HPLC analyses were carried out on a Purosphere STAR RP-18e 250 x 4.5 mm column $(5 \mu)$ (Darmstad, Germany).

Separation was achieved using a mobile phase consisting of water: acetonitrile: triethilamine: glacial acetic acid $(70: 29.16: 0.52: 0.33 \mathrm{v} / \mathrm{v})$, at $\mathrm{pH}=$ 5.5 and a flow rate of $1 \mathrm{~mL} / \mathrm{min}$. The eluted compounds were monitored at $294 \mathrm{~nm}$. The column was maintained at ambient temperature, and an injection volume of $20 \mu \mathrm{L}$ was used. Chromatographic run was 10 minutes.

The mobile phase was filtered through 0.45 micron membrane filter and ultrasonicated for 10 minutes prior to use. Peak homogeneity was expressed in terms of peak purity values and was obtained directly from spectral analysis report obtained using the instrument software.

\subsection{Application of the method}

This assay was carried out in accordance with Ethical Committee of the University, and all of patients signed informed consent forms. Blood of ten patient volunteers who were in treatment with risperidone (4 $\mathrm{mg}$ daily), were used for quantification of the drug from serum. The collection of the samples was done in the morning, before the next administration of the drug.

Serum was separated from plasma by heating to $37^{\circ} \mathrm{C}$ and centrifugation of blood samples at $3000 \mathrm{rpm}$ for ten minutes. The volume of serum used for experiment was $1 \mathrm{~mL}$.

\section{RESULTS AND DISCUSSION}

\subsection{Method optimization}

Different conditions for sample extraction of risperidone and chromatographic conditions was tried to achieve optimal results. A Design of Experiments was performed (3-level factorial design: $3^{\wedge} 3$ ) to optimize the chromatographic parameters, choosing as study parameters the mobile phase flow, $\mathrm{pH}$ of mobile phase, and the column temperature. A pool of standard risperidone extracts with concentration of $30 \mu \mathrm{g} / \mathrm{mL}$ was used. By Statgraphics ( S Software, area and height of chromatographic peaks, as its purity were the more important parameters. Quantifications were done in triplicate, by $\mathrm{LC} /$ DAD.

The selection of the mobile phase was carried out on the basis of polarity i.e., with a satisfactory separation of risperidone and the internal standard desipramine with good peak symmetry (system suitability test). Moreover, it allows a fast running time of 7 minutes.

Several trials for optimization of the mobile phase were taken and finalized as water: acetonitrile: triethilamine: glacial acetic acid (70:29.16:0.52: 0.33 $\mathrm{v} / \mathrm{v})$.

Several wavelengths were tried, chosen $294 \mathrm{~nm}$ as working wavelength. Complete resolution of the peaks with clear baseline separation was obtained of this way.

Sample extraction was optimized to eliminate the laborious extraction steps, with minimal losses of risperidone and very good recoveries from spiked serum samples and from real samples.

Optimization of chromatographic parameters for human serum as matrix: the optimal conditions found taking as response the peak purity, and the optima chromatographic conditions were: mobile phase flow $1.0 \mathrm{~mL} / \mathrm{min}$, water phase $\mathrm{pH}: 5.5$, and column temperature: $25^{\circ} \mathrm{C}$

\subsection{Calibration curves}

Calibration curves were constructed for the range of $1-60 . \mathrm{ng} / \mathrm{mL}$. Each solution $(1.5,20,30,45$ and $60 \mathrm{ng} / \mathrm{mL})$ was injected three times. This range of solution concentrations include the risperidone concentrations expected in serum: $2.9 \mathrm{ng} / \mathrm{mL}(80 \% \text { range: } 0.9-27.9 \mathrm{ng} / \mathrm{mL})^{3-4}$.

Standard curves were constructed by plotting the peak area ratio of the analyte to the internal standard as a function of the concentration added.

The mean equation (curve coefficients \pm standard deviation) for the calibration curve $(\mathrm{n}=5)$, obtained from five points, was $y=0.0074 \mathrm{x}( \pm 0.1) \mathrm{x}$
+0.067 , with a correlation coefficient, $r=0.999$.

\subsection{Precision and accuracy}

The intra-assay precision of the assay was measured by the percent coefficient of variation (RSD) over the concentration range of low (L), medium $(\mathrm{M})$, and high $(\mathrm{H})$ quality control levels $(1-30-60 \mathrm{ng} / \mathrm{mL})$ for three replicates each in the same analytical run (each replicate was spotted three times), and intra-assay accuracy was measured from percentage recoveries obtained by the analyzes of the quality control samples, determined by linear regression equation of peak area vs. drug concentration. Inter-assay precision and interassay accuracy were calculated after repeated analysis in three different analytical runs. Each experiment included the sample extraction step.

Accuracy values were between $90.82 \%$ and $98.56 \%$ of recovery percentage.

Precision and accuracy did not exceed $3.93 \%$ of RSD at any level. The results are presented in Table 1 and Table 2.

Table 1. Precision of the method.

\begin{tabular}{|ccc|}
\hline \multicolumn{3}{|c|}{ Relative standard deviation (RSD), \% } \\
\hline \multirow{2}{*}{ Concentration $(\mathrm{ng} / \mathrm{mL})$} & Intra-assay $^{\mathrm{a}}$ & Inter-assay $^{\mathrm{b}}$ \\
\hline \multirow{2}{*}{1.00} & 2.09 & 3.25 \\
30.00 & 1.59 & 1.77 \\
60.00 & 0.52 & 0.79 \\
\hline
\end{tabular}

${ }^{a} \mathrm{n}=3$; analyzed on the same day (three solutions of each concentration)

${ }^{b} \mathrm{n}=9$; analyzed on three different days (three solutions of each concentration prepared for 3 days)

Table 2. Method accuracy.

\begin{tabular}{|cccc|}
\hline $\begin{array}{c}\text { Actual concentration } \\
(\mathrm{ng} / \mathrm{mL})\end{array}$ & $\begin{array}{c}\text { Measured concentration } \\
(\mathrm{ng} / \mathrm{mL})\end{array}$ & Accuracy, \% & RSD, \% \\
\hline 1.00 & $0.97 \pm 0.04$ & 90.82 & 3.93 \\
30.00 & $29.46 \pm 0.71$ & 98.44 & 2.44 \\
60.00 & $61.05 \pm 1.11$ & 98.56 & 1.82 \\
\hline
\end{tabular}

\subsection{Detection and quantification limits}

The limit of detection (LOD) and limit of quantification (LOQ) were calculated preparing solutions at three concentrations $(0.2-0.5-1.0 \mathrm{ng} / \mathrm{mL})$ in the lower range of linear regression curve.

LOD was $0.40 \mathrm{ng} / \mathrm{mL}$ and LOQ was $0.87 \mathrm{ng} / \mathrm{mL}$, determined using the equations: $\mathrm{LOD}=3.3 \mathrm{\sigma} / \mathrm{b} ; \mathrm{LOQ}=10 \sigma / \mathrm{b}$, where $\sigma$ is the standard deviation of the responses, and "b" corresponds to the slope obtained from the curve peak area ratio of the analyte to the internal standard versus concentration of the analyte. These values were experimentally verified applying the method to prepared solution with these analyte concentrations.

\subsection{Selectivity}

The method selectivity was demonstrated on three blank serum samples obtained from healthy volunteers; the chromatograms were found to be free of interfering peaks. Risperidone and the internal standard desipramine were well resolved, with $\mathrm{tR}=3.82$ for risperidone, and 7.55 for desipramine (Fig. 2). Selectivity between risperidone and its major metabolite was not assay because the aim of the study was obtained a LC/DAD method useful to evaluate pharmacotherapy adherence, therefore, it is not important that the parent drug is well resolved from its metabolites.

\subsection{Extraction recovery}

The extraction recovery of risperidone from serum and that of the internal standard were quantified using the concentrations of 1,30 and $60 \mathrm{ng} / \mathrm{mL}$ for the drug and concentration of $0.5 \mathrm{ng} / \mathrm{mL}$ for the internal standard. The extraction recoveries were calculated by comparing the observed concentrations obtained from the processed standard samples to the concentrations obtained from the standards solutions added to the serum after the extraction, which represented $100 \%$ recovery. The extraction recovery of risperidone from serum ranged from $90.5 \%$ to $96.5 \%$. The internal standard extraction recoveries were found between $91.5 \%$ and $95.8 \%$.

\subsection{Application of the method}

The risperidone concentration ranged between $1.52 \mathrm{ng} / \mathrm{mL}$ to $7.91 \mathrm{ng} / \mathrm{mL}$. 
Risperidone plasma concentrations had been of $2.9 \mathrm{ng} / \mathrm{mL}(80 \%$ range, $0.9-27.9 \mathrm{ng} / \mathrm{mL})$ in chronic use ${ }^{3-4}$, therefore, all of values found in the samples studied were at therapeutic range.

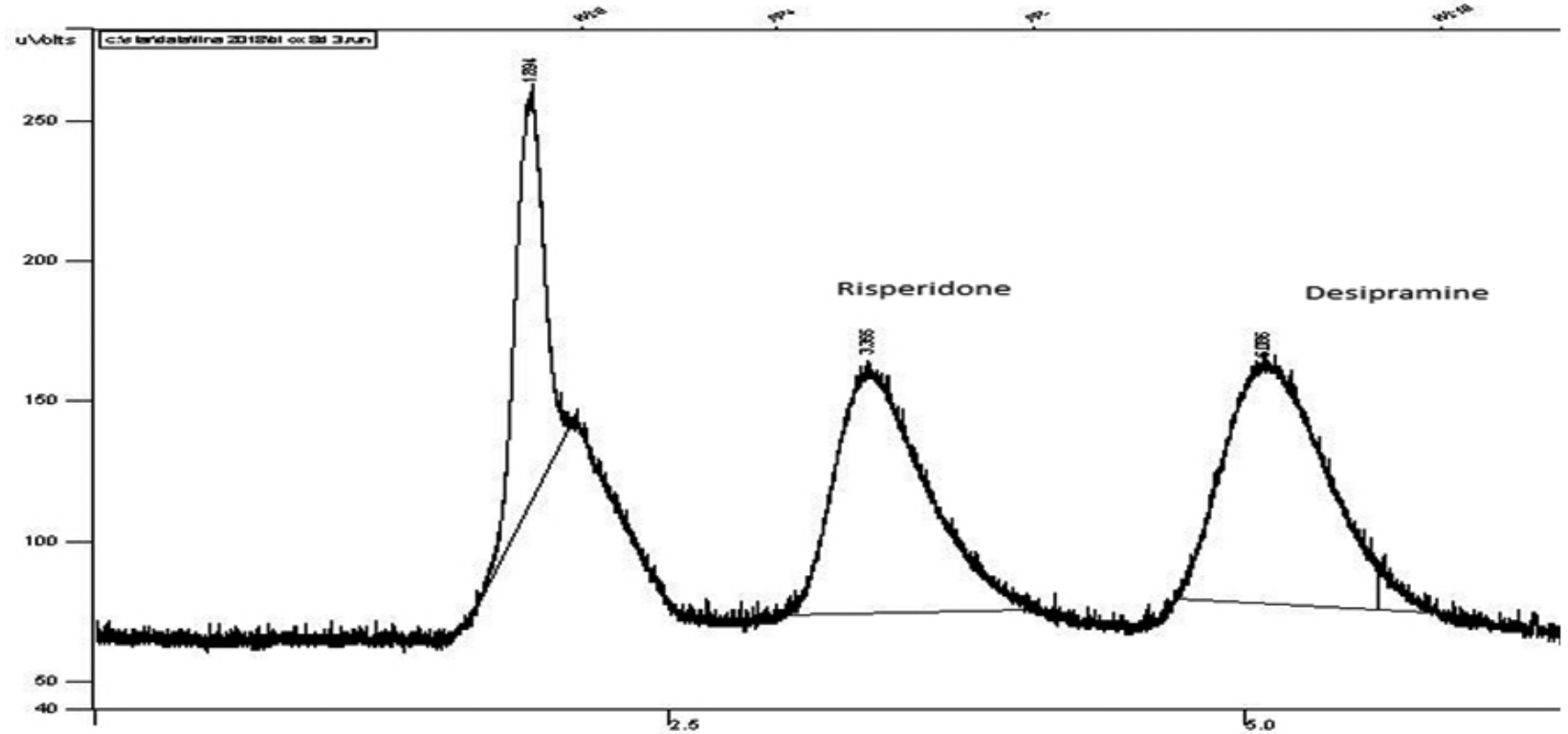

Figure 2: Selectivity between risperidone and the internal standard desipramine. Peak $\mathrm{n}^{\circ} 1$ : risperidone; peak $\mathrm{n}^{\circ} 2$ : desipramine.

\section{4.- CONCLUDING REMARKS}

The developed LC/DAD method is simple, rapid, precise, sensible, selective and accurate for quantitative determination of risperidone in human serum. The method works with a simple liquid-liquid extraction step and it was designed to cover the usual serum concentration level of patients taking the drug ${ }^{3-4}$.

The most significant advantages of the present LC/DAD method, as difference of other analytical methods founded in bibliography to quantify risperidone in biological fluids, are the small sample volume needed, few running time, few injection volume, and better sensitivity and selectivity. Among all different detectors used to analyze risperidone (ELSD, RID, UV, MS, etc), UV-DAD is simplest and suitable for the purpose of this work. Moreover, serum instead plasma as blood sample allows an easy and fast extraction of analyte from matrix. The limit of quantification and recovery are more than adequate for use in pharmacokinetic studies. Our results indicate that this $\mathrm{LC} / \mathrm{DAD}$ procedure is a reproducible method that provides consistent quantification of risperidone in human serum.

Therefore, the developed LC/DAD method is useful for quantification of risperidone in human serum, suitable for pharmacotherapy adherence studies.

\section{ACKNOWLEDGEMENTS}

The authors would like to thank the Research Council at the University of Concepción (Project VRID Enlace nº 216.074.053-1.0).

\section{REFERENCES}

1. G. Mc Evoy. AHFS Drug Information. American Society of HealthSystem Pharmacists, 2015.

2. S. Sweetman. Martindale, Guía Completa de Consulta Farmacoterapéutica. Pharma Editores S.L., Barcelona, 2008.

3. A.E. Balant-Gorgia, M. Gex-Fabry, C.H. Genet, L.P. Balant LP, Ther. Drug Monit. 21, 105-115., (1999)

4. S.Y, Dong, J.S. Sook, Y. Young-Ran, J. Psycopharmacol., 147 300-305, (2013)

5. P.M.Haddad, C. Brain, J. Scott, Patient Related Outcome Measures, 5, 43-62, (2014)

6. S.C. Marcus, J. Zummo, A.R. Pettit, J. Stoddard, J.A. Doshi, JMCP, 21, 754-68, (2015)

7. W. Yin Lam, P. Fresco, Bio Med Research International, 1, 1-12, (2015)
8. D.I. Velligan, M. Sajatovic, A.Hatc, P. Kramata, J.P. Docherty, Patient Prefer. Adherence, 11,449-468, (2017)

9. S.V. Phan, International Journal of Psychiatry in Medicine, 51,211-9, (2016)

10. N.H. Sharaya, M.F Dorrell, N.A. Sciacca, JPP, 30, 37-41, (2017)

11. M. Grundmann, I. Kacirova, R. Urinovska, Acta Pharm., 64, 387-401, (2014)

12. S.M. Foroulan, A. Zarghi, A. Shafaati A. Iranian Journal of Pharmaceutical Research, 5, 37-70, (2006)

13. B. Cabovska, A. Vinks, J, Chromatogr., B, 852, 497-504, (2007)

14. H. Karadeniz, JJC, 13, 57-67, (2018)

15. P. Torres, M.J. Sepúlveda, C.von Plessing, J. Chil .Chem., Soc., 56, 606$609,(2011)$

16. K. Tonooka, L. Yoshida, K. Tomobe, Y. Kunisue, M. Terada, T.Shinozuka AJAC, 9, 88-97, (2018)

17. I. Lakshmi Prasanna, G.T. Naidu, N. Fathima, I.E. Chakravarthy, G. Abdul Huq, IJPPR, 12, 148-159, (2018) 